www.jmscr.igmpublication.org

Impact Factor (SJIF): 6.379

Index Copernicus Value: 71.58

ISSN (e)-2347-176x ISSN (p) 2455-0450

crossref DOI: https://dx.doi.org/10.18535/jmscr/v6i6.139

Journal Of Medical Science And Clinical Research

IGM Publication

An Official Publication of IGM Publication

\title{
Awareness of anaemia during pregnancy among the pregnant women attending a health facility in District Srinagar
}

\author{
Authors \\ Dr Mahk Nelofar ${ }^{1}$, Dr Mohsina Mukhtar ${ }^{2}$, Dr Hina Bashir ${ }^{3}$ \\ Prof (Dr) S. Mohammad Salim Khan ${ }^{4}$, Dr Ruqia Quansar ${ }^{5}$ \\ 1,2,35 MD Social and Preventive Medicine \\ ${ }^{4}$ HOD of Social and Preventive Medicine \\ Govt Medical College Srinagar, India
}

\begin{abstract}
Background: Anaemia is the most common nutritional deficiency disorder in the world. As per WHO report, the prevalence of anaemia in developed and developing countries in pregnant women is 14 percent and 51 percent in developed and developing countries respectively. In India, prevalence of anaemia among pregnant women is 65-75 percent as WHO report. Anaemia is one of the most important deciding factors for the outcome of pregnancy. Effects of anaemia among pregnant women include increased risk of low birth weight, prematurity, perinatal and neonatal mortality, and increased risk of maternal morbidity and mortality. Anaemia is estimated to contribute to more than 115,000 maternal deaths and 591,000 perinatal deaths globally per year. The objective of this study was to assess the awareness of anaemia during pregnancy among the pregnant women attending a health facility in District Srinagar.

Methodology: All pregnant women attending the health care facility from April, 2016 to June, 2016. A total of 110 pregnant women were included in this study. The women were interviewed using pre structured questionnaire.

Results: Majority women were in the age group > 25 years $(51 \%)$, literate $(62 \%)$ and para $(>2)$ were $47 \% .68 \%$ were unaware of the symptoms of anaemia, $96.2 \%$ were unaware of cardiac complications, postpartum haemorrhage and maternal mortality. $58 \%$ were unaware that iron rich food can improve anaemia and $94.6 \%$ were unaware that iron should not be taken with milk, coffee and tea.

Conclusion: There is lack of knowledge regarding grave complications of anaemia in pregnancy. There is a need for generating awareness among pregnant women regarding prevention and treatment of anaemia in pregnancy. The role of mass media in imparting the knowledge can't be ignored.
\end{abstract}

\section{Introduction}

Anaemia is the most common nutritional deficiency disorder in India. According to WHO, prevalence of anaemia among pregnant women in developed countries is about $14 \%$, whereas it is still as high as $51 \%$ in the developing world ${ }^{(1)}$. In
India the prevalence of anaemia among pregnant women is about $65-75 \% \%^{(1)}$.

Worldwide, it is estimated that about 20 per cent of maternal deaths are caused by anaemia; in addition, anaemia contributes partly to 50 per cent of all maternal deaths. First, anaemia reduces 
women's energy and capacity for work and can therefore threaten household food security and income. Second, severe anaemia in pregnancy impairs oxygen delivery to the foetus and interferes with normal intra-uterine growth, resulting in intrauterine growth retardation, stillbirth, LBW and neonatal deaths. Therefore, anaemia is a major contributor to poor pregnancy and birth outcomes in developing countries as it predisposes to premature delivery, increased perinatal mortality and increased risk of death during delivery and postpartum

Anaemia is estimated to contribute to more than 115,000 maternal deaths and 591,000 perinatal deaths globally per year ${ }^{(4)}$. The new Global Nutrition Report 2017 placed India at the bottom of the table with maximum number of women impacted with anaemia in the world, followed by China, Pakistan, Nigeria and Indonesia. The only way to prevent maternal death arising from anaemia is by early detection and effective management in addition to creating awareness and health education. Implementation of any programme to reduce the incidence and prevalence of anemia in pregnant women needs participation of the beneficiaries which again is affected by the awareness of the benefits among the caregivers.

This study focuses on the prevalence of awareness of anemia among antenatal women reporting to primary health centre and association of knowledge and practice of taking iron rich food and literacy of participant, awareness of symptoms of anaemia, knowledge of affects of anaemia in pregnancy.

\section{Aims and Objectives}

To find out the awareness of anaemia during pregnancy among pregnant women attending primary health centre.

\section{Materials and Methodology}

Study population: pregnant women with anaemia attending primary health care facility.
Study Design: Cross-sectional, hospital based study.

Study Area: Block Hazratbal, district Srinagar.

Study Period: April 2016 to June 2016.

Sample Selection: All anaemic antenatal patients attending outdoor patient and indoor patient were included.

The women were interviewed using semi structured questionnaire, after obtaining informed consent.

Statistical analysis- Data was analysed using SPSS statistics version 23.

\section{Results}

In our study, 110 antenatal women belonging to age group $>25$ years $(51 \%)$ were interviewed about their awareness regarding anaemia, among them $40(36.3 \%)$ belonged to urban area and 70(63.6\%) belonged to rural area, majority of them belonged to joint family $78(70.9 \%)$ and only $32(29 \%)$ were from nuclear setup. 94(85.4) of the study participants were homemakers and 16(14.5) were working women's, Para $(>2)$ were $47 \%$, about (96.2\%) were unaware of cardiac complications, postpartum haemorrhage and maternal mortality.

Table: 1

\begin{tabular}{|l|c|}
\hline Demographic profile & $\mathrm{N}(\%)$ \\
\hline Residence: & \\
\hline Urban & $40(36.3)$ \\
\hline Rural & $70(63.6)$ \\
\hline Type of family & $32(29)$ \\
\hline Nuclear & $78(70.9)$ \\
\hline Joint & \\
\hline Occupation & $94(85.4)$ \\
\hline Homemaker & $16(14.5)$ \\
\hline Working women
\end{tabular}

Fig 1: literacy status among study participants.

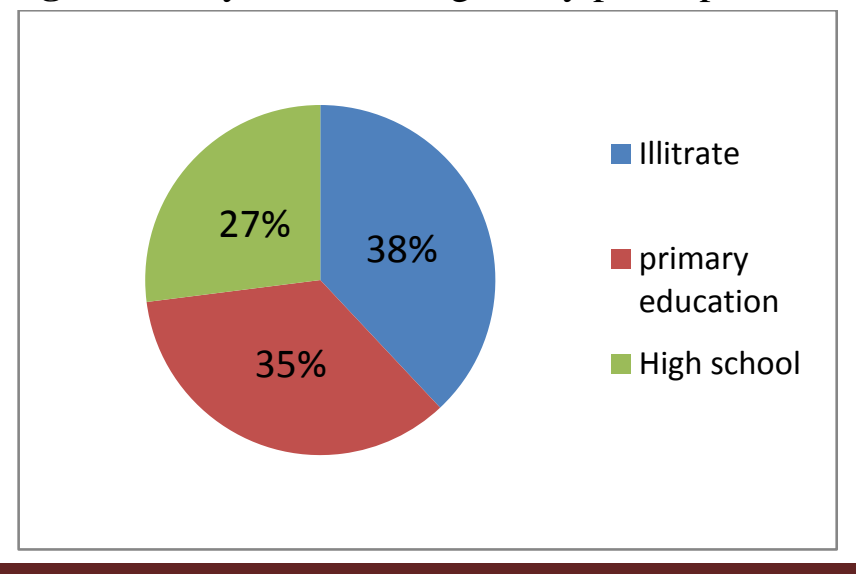


In our study, among 110 study participants $38 \%$ were ilitrate, $35 \%$ had primary education, and $27 \%$ had up to high school.

Fig 2: Awareness of symptoms of anaemia among study participants.

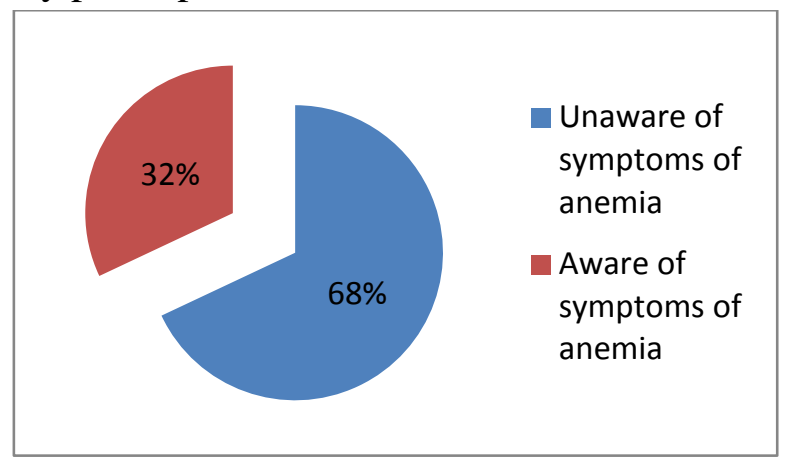

Among 110 study participants only 32\% were aware of symptoms of anaemia and $68 \%$ were unaware of it.

Fig 3: Knowledge of effects of anaemia in pregnancy.

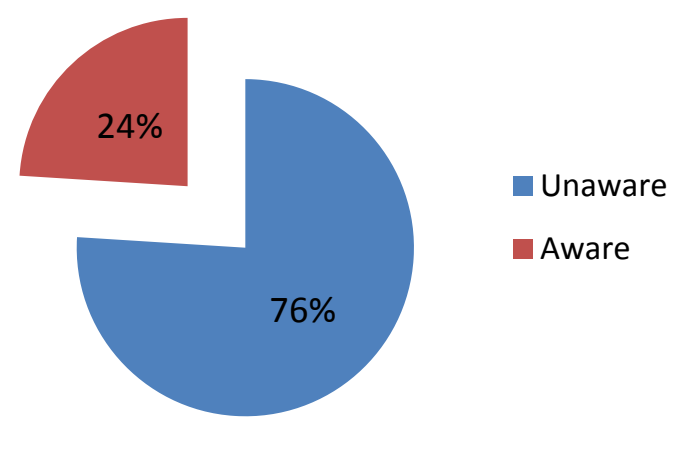

Among 110 study participants only $24 \%$ had knowledge about effects of anaemia in pregnancy and $76 \%$ were unaware of it.

Fig 4: Knowledge of iron supplements in pregnancy.

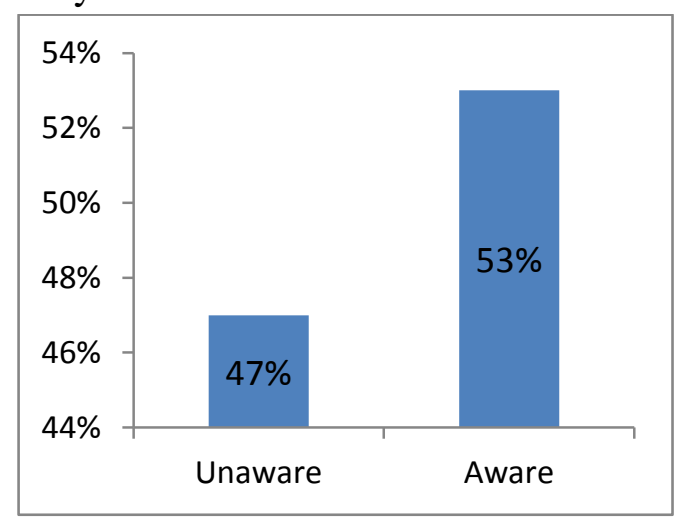

Among study participants, majority (53\%) of them were aware of iron supplements, iron injections in pregnancy, and only $47 \%$ didn't have any knowledge regarding it.
Figure 5: Distribution of study population based on iron intake

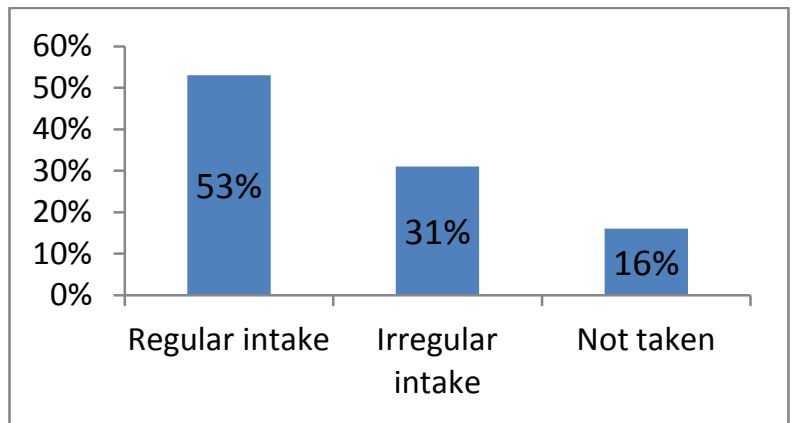

In our study $53 \%$ had a regular intake of iron supplements, $31 \%$ had irregular intake, and $16 \%$ had not taken iron supplementation.

Fig 6: Knowledge regarding food which can improve anaemia

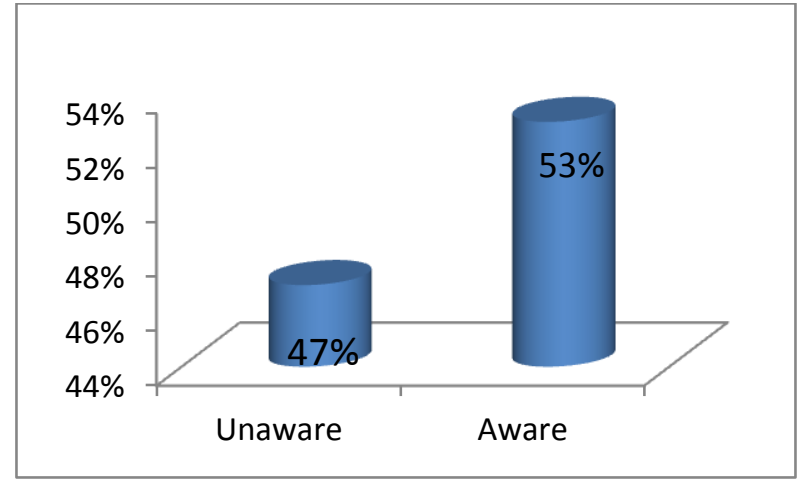

Majority (58\%) were unaware of food which can improve anaemia in pregnancy.

\section{Discussion}

In our study, among 110 study participants $36.3 \%$ belonged to urban area and $63.6 \%$ belo to rural area, majority of them belonged to joint family $70.9 \%$ and only $29 \%$ belong to nuclear family,85.4 of the study participants were homemakers and 14.5 were working womens.

In our study, among 110 study participants $38 \%$ were ilitrate, $35 \%$ had primary education, and $27 \%$ had up to high school which is similar to Narahari et al (2015) $41.3 \%$ were illiterate, $38 \%$ had a primary education, $14.7 \%$ had made it upto $10^{\text {th }} / 12^{\text {th }}$, and only $6 \%$ were graduates/ postgraduates.

The present study reveals that $32 \%$ were aware of symptoms of anaemia and $68 \%$ were unaware of it,which is similar to Narahari et al (2015) in that they found $70 \%$ were aware and $34 \%$ were unaware. 
Among 110 study participants only $24 \%$ had knowledge about effects of anaemia in pregnancy and $76 \%$ were unaware which is different from Narahari et al (2015), where they found 79\% were aware and $21 \%$ were unaware of reffect of anemia in pregnancy.

Among study participants, majority (53\%) of them were aware of iron supplements, iron injections in pregnancy, and only $47 \%$ don't have knowledge regarding iron supplementation which is similar to Narahari et al (2015) in which they found that $48 \%$ were aware of iron supplements' and $52 \%$ were not.

In our study, we found that $53 \%$ of participants had a regular intake of iron suppliments, $31 \%$ had irregular intake, and $16 \%$ had not taken iron supplementation which is less and we need to emphasize on regular intake and distribution of iron supplements.

\section{Conclusion}

Our present study shows the lack of knowledge among pregnant women's regarding anemia and its complications. Demographic, socioeconomics and literacy status influences the grave outcomes of anemia and its complications. Creating awareness about iron supplementation and health education can grossly reduce the incidence of anemia in antenatal population and thereby prevents anemia related mortality and morbidity. There is a need for generating awareness among pregnant women regarding prevention and treatment of anaemia in pregnancy. The role of interpersonal communication, door to door surveys and mass media in imparting the knowledge can't be ignored. It is a need of the hour to disseminate this basic knowledge which can have an impact on our health care system.

\section{Recommendation}

We recommend regular health check up and iron folic acid distribution to all identified pregnant women's.
All pregnant women's should be registered to health personal within first trimester and regularly followed up.

All antenatal anemic womens should in investigated and treated properly as early as possible to avoid postpartum morbidity and mortality.

\section{References}

1. Worldwide prevalence of anaemia 19932005 WHO Global Database on Anaemia

2. ACOG: Nutrition and woman. Education Bulletin no.229, oct 1996

3. Gautam VP, Bansal Y, Tanjeja DK, Ingle GK. A study on compliance to iron-folic acid therapy and its effects on anemia during pregnancy. Indian J Prev soc Med 2005;369:102-7.

4. Yadav RK, Banjade B. Knowledge and practice of anemia among pregnant women attending antenatal clinic in Dr. Prabhakar Kore Hospital, Karnataka - A cross sectional study. IOSR J Dent Med Sci 2014;13:74-80.

5. Dorairajan G, Palanivel C, Sakthi D. Influence of awareness and attitude about anemia and iron supplements on prediction of anemia among pregnant women. BJOG 2014;121:153-76.

6. Narahari P, Kirubamani H. International Journal of Scientific and Research Publications, Volume 5, Issue 3, March 20152 ISSN 2250-3153.

7. Neveditha K, Shanthini NF. Knowledge, attitude and practises of pregnant women regarding anemia, iron rich diet and iron supplements and its impact on their $\mathrm{Hb}$ levels. Int J Reprod Contracept Obstet Gynecol 2016;5:425-31. 